\title{
ОБ ОПЫТЕ УЧЕНЫХ-ПЕДАГОГОВ В СОВРЕМЕННОМ ОБРАЗОВАНИИ
}

\section{ABOUT THE EXPERIENCE OF SCIENTISTS- TEACHERS IN MODERN EDUCATION \\ K. Bogonosov \\ D. Vorobyev \\ L. Ponomareva \\ S. Sadekova \\ V. Moiseev}

Summary: The article concerns the one of the topical areas of pedagogical science that claim to be undoubtedly modern - mobile learning. The relevance of the topic under consideration is not questioned by educational scientists, which is actually confirmed in the article. The lack of knowledge of the subject area is also not denied. The possibilities of using didactic tools, jointly formed by both teachers and the students themselves, are considered. This encourages students to act as active subjects of the entire educational process. Students should be encouraged to write down, discuss and document their ideas, and share their "useful" technology strategies and practices. Practice shows that the time spent in the classroom (classroom) in the framework of such educational activities is especially appreciated by students and encourages the development of literacy (including digital). Educational content in the modern educational process can be created by a teacher, selected by him from existing developments, and can also be "compiled" (collected with the active participation of the students themselves). This thesis is important for all aspects of organizing educational interaction. The combination of the correct choice of pedagogical technologies and the ability to access modern information resources is a prerequisite for significant progress in successful educational activities in the development of educational content.

Keywords: modern education, mobile pedagogics, mobile learning, mobility, pedagogical technologies, teaching methods.
Богоносов Константин Александрович

к.т.н., Доцент, Московский государственный университет технологий и управления им. К.Г. Разумовского (ПКУ) kbogonosov@gmail.com

Воробьев Дмитрий Игоревич к.э.н., Дочент, Московский государственный университет технологий и управления им. К.Г. Разумовского (ПКУ) d.vorobyev@mgutm.ru

Пономарева Лиля Фаясовна к.б.н., Дочент, Московский государственный университет технологий и управления им. К.Г. Разумовского (ПКУ) eponomarev@mfmgutu.ru

Садекова София Равилевна

Московский государственный университет технологий и управления им. К.Г. Разумовского (ПКУ)

s.sadekova@mgutm.ru

Моисеев Виктор Александрович

Московский государственный университет технологий и управления им. К.Г. Разумовского (ПКУ)

Аннотация: Настоящая статья посвящена одной из актуальных областей педагогической науки, претендующих на звание безусловно современных, мобильного обучения. Актуальность рассматриваемой темы не подвергается сомнению учеными-педагогами, что фактически подтверждается в статье. Также не отрицается недостаточная изученность предметной области. Рассмотрены возможности использования дидактического инструментария, совместно формируемого как преподавателями, так и самими обучающимися. Это побуждает обучающихся выступать в качестве активных субъектов всего образовательного процесса. Следует поощрять обучающихся записывать, обсуждать и документировать свои идеи, поделиться своими «полезными» технологическими стратегиями и практиками. Практика показывает, что время, проведенное в аудитории (классе) в рамках подобной учебной активности, особенно ценится обучающимися и поощряет развитие грамотности (в том числе цифровой). Обучающий контент в современном образовательном процессе может быть создан преподавателем, выбран им из существующих наработок, а также может быть «скомпилирован» (собран при активном участии самих обучающихся). Данный тезис важен для всех аспектов организации учебного взаимодействия. Сочетание правильного выбора педагогических технологий и возможности доступа к современным информационным ресурсам, является необходимым условием существенного прогресса в успешной учебной деятельности по освоению учебного контента.

Ключевые слова: современное образование, мобильная педагогика, мобильное обучение, мобильность, педагогические технологии, методы обучения.

учение. Этой сфере научного знания посвящена настоящая статья.

Актуальность рассматриваемой темы обычно не подвергается сомнению учеными-педагогами: «мобильное 
обучение является одним из наиболее активно развивающихся видов электронного обучения, важным моментом которого являются его качественная организация, в частности, при выработке стратегии и контроля получения информации с помощью мобильных технологий, обеспечения ее результативности, достоверности и актуальности» $[13$, с. 73]

При этом подчеркивается недостаточная изученность предметной области: «Если в повседневной жизни преимущества использования мобильных технологий практически бесспорны, то вопрос об их интеграции в процесс обучения все еще открыт. Исследование внедрения мобильных технологий в процесс обучения находится в начале пути своего развития» [8, с. 21].

Так, например, российский ученый-педагог В.А. Куклев утверждает: «Мобильное обучение предусматривает наличие мобильных средств, независимо от времени и места, с использованием специального программного обеспечения на педагогической основе междисциплинарного и модульного подходов» $[6$, с. 46].

Часто в качестве результата своих научных изысканий отечественные педагоги публикуют нечто подобное: «российские исследователи и педагоги-практики должны постоянно заниматься поиском наиболее совершенных и современных методов и технологий мобильного обучения. Однако внедрение их в педагогический процесс образования сопровождается, во-первых, рядом проблем дидактического характера, а во-вторых, - проблем информационного характера» [1, с. 28].

Или своеобразное проявление «дарвинизма» в педагогике Н.Б. Ковалевой: «медиапространство события нашего современника может быть понято и проблематизировано с психолого-антропологической точки зрения как новая (дополняющая традиционную среду обитания и конкурирующая с ней за ресурсы и привилегированный статус) сфера деятельности и самореализации современного человека» [4, с. 11].

Попытка вернуться в рамки традиционного методологического аппарата исследования приводит к подобным формулировкам выявленного противоречия: «многие образовательные учреждения стали вводить новые элементы в свою деятельность, но педагогическая практика преобразований столкнулась с противоречием между имеющейся потребностью в быстром развитии и неумением педагогов это делать» [1, с. 27].

Объектом изучения предлагается считать расширенное «пространство знаний образовательной организации (т.е. содержание знаний всех субъектов образовательного процесса) и информационное пространство образовательной организации, т. е. методы, формы, средства, технологии управления знаниями» $[8$, с. 63].
Инновационность мобильного обучения определяется, как «комплексная деятельность по созданию (рождению, разработке), освоению, использованию и распространению новшества» [1, с. 25]. При этом, в отношении объекта обучающей деятельности должен сохраняться сложившийся (в традиционных образовательных системах) «баланс между социальными и индивидуальными потребностями» [1, с. 26].

Мнения педагогов-исследователей из стран, столкнувшихся с феноменом M-learning (мобильного обучения) значительно раньше Российской Федерации (Ally, M., Andersson, A., Aresta, M., Kisko, D., Prieto-Blazquez, J., Santos, C., и др.), могут быть обобщенно представлены лаконично примерно следующим образом: «это обучение с помощью мобильных устройств в любое удобное время и в любом месте» [10; 14, с. 101].

В любом случае нельзя не согласиться с авторитетным мнением В.И. Слободчикова: «В образовательном знании речь идет о новом типе научности» [9, с. 141].

Это побуждает обучающихся выступать в качестве активных субъектов всего образовательного процесса. Следует поощрять обучающихся записывать, обсуждать и документировать свои идеи, поделиться своими «полезными» технологическими стратегиями и практиками. Практика показывает, что время, проведенное в аудитории (классе) в рамках подобной учебной активности, особенно ценится обучающимися и поощряет развитие грамотности (в том числе цифровой).

Обучающий контент может быть создан преподавателем, выбран им из существующих наработок, а также может быть «скомпилирован» (собран при активном участии самих обучающихся). Данный тезис важен для всех аспектов организации учебного взаимодействия. Здесь можно привести следующие рекомендации:

- предложить обучающимся составить собственные (в том числе мультимедийные) тезаурусы (словари) для всей своей группы (всего класса).

- предложить обучающимся составить индивидуальные записи, содержащие примеры новых (для конкретного слушателя) определений, иллюстраций, например, с помощью Evernote - https:// evernote.com/.

Следует признать педагогически оправданным прием, когда обучающихся могут попросить исследовать и публиковать результаты анализа в текстах (в т.ч. в гипертестовом формате) с возможностью группового обсуждения и комментирования. Для этой цели вполне подходит инструмент «Padlet», реализованный в онлайн версии на соответствующем Интернет-ресурсе (http://padlet.com/). После этого обучающимся следует предложить выбрать и опубликовать (то есть, «курировать») различные мультимодальные тексты для на ос- 
нове критической оценки таких текстов других обучающихся. В результате этого обучающиеся создают свои собственные мультимедиа тексты для публикации создавая таким образом обратную связь в блоге класса.

Обучение и использование различных технологий может быть организовано под руководством самого обучающегося и включать несколько уровней связей между обучающимися и их кураторами - более опытными пользователями, в том числе дистанционно.

Здесь уместно предложить обучающимся самостоятельно выбрать набор онлайн-инструментария для повышения их мотивации и самооценки. В качестве такого инструментария можно использовать мобильные социальные сети, такие как Facebook, Twitter, и т.д.

Рассмотрим возможности использования этих инструментов, по предложению как от преподавателей, так и от самих обучающихся:

- обучающиеся могут играть активную роль в определении их собственных коммуникативных потребностей, принимая фотографии мест и ситуаций, в которых они «застряли», и делать заметки или голосовые записи проблем. Конечно, обучающиеся могут делать заметки в блокноте спросить в классе, но изображения и записи представляют собой более богатые воспоминания для добавления к контексту нарастающим итогом.

Необходимость позиционирования обучающимся процесса их лингвистического обучения как динамической системы. В контексте данного требования необходимо учитывать следующее:

- преподаватели уже обеспечивают такую динамику как в рамках аудиторной работы, так и во внеклассном обучении с использованием различных тщательно выбранных текстовых фрагментов и мультимедиа;

- обучающиеся могут получить мобильный доступ к образовательному контенту и выбирать источники на своих устройствах, включая звук, изображения, видео и письменные тексты через подкасты, мультимедийные презентации от веб-источников, таких как Slideshare, YouTube, электронные книги или PDF-файлы. Обучающиеся также могут поделиться некоторыми из них с преподавателями и сверстниками.

Необходимо предоставление обучающимся своевременной обратной связи и лестницы для карьерного роста:

- преподаватели и обучающиеся могут «захватывать» несколько мимолетных моментов взаимодействия в классе наряду с более детализированными результатами запланированного языкового роста выходом, таким как в виде презентаций с использованием голосовых или видео функций записи на своих мобильных устройствах. Эти записи позволяют преподавателям и обучающимся перемотать, пересмотреть, а затем на этом основании оценить прогресс в освоении предметной области, а также сохранить и поделиться своим мнением для оценки успешности в достижении целей.

- Самооценка, отзывы коллег и преподавателей, также как отчет о текущем прогрессе или развитии нужды значительно облегчают мониторинг успешности языкового обучения, благодаря сделанным записям в аудитории (классе) или вне его. Эти стратегии для обратной связи педагогически оправдывает использование мобильных устройств в образовательных целях.

Известные ученые-исследователи возможностей и ограничений мобильной педагогики [5; 8; 10; 15; 17], по всей вероятности, одобрили бы возникновение ситуаций, когда преподаватели перемещаются из одного места в аудитории в произвольное другое место, оставаясь способными оказать обучающимся дидактическую и воспитательную помощь [13; 14; 16; 17].

Не менее важным представляется предоставление возможностей для обучающихся взаимодействовать в обществе, вести переговоры и производить разнообразное и «креативное» общение со сверстниками (преодолевая временные и пространственные ограничения):

- Потребность в оперативной реакции на нарушение связи в совместной групповой работе может возникнуть в случае, когда преподаватель может быть временно недоступен при работе с отдельными группами обучающихся. Разумная консультация и использование справки на ресурсы на мобильных устройствах, такие как словари и переводчики способны облегчить и облегчают общение в такой педагогической ситуации настолько, насколько обучающиеся вынуждены будут решать свои языковые проблемы внутри и за пределами учебной аудитории.

- Многие преподаватели сообщали о том, что испытывают беспокойство по поводу потенциала использования мобильных устройств для прерывания совместной работы и вмешательства во взаимодействие, отвлечение внимания обучающихся от того, что происходит перед ними. Однако, как и в реальной жизни, для того, чтобы связь не прерывалась ненадлежащее использование мобильных устройств во время социального взаимодействия может быть ограничено.

- преподаватели (особенно - опытные) знают о преимуществах в области устного общения, которые имеют обучающиеся, получившие возможность два или три раза «отрепетировать», попробовать свои устные умения в общении, например, 
в ролевой игре. Это может быть апробировано на подготовительном этапе, когда происходит объединение языковых ресурсов в парах или группах, а затем в процессе репетиций в группе.

- предоставление обучающимся возможности записать короткий раздел репетиции, и попросить их слушать, размышлять, исследовать и корректировать эти короткие записи совместно означает, что их окончательная версия будет в результате сильнее. Если обучающиеся записывают подобные короткие разделы, чтобы сравнить с их с ранними или поздними версиями, уверенность и мотивация к учебной деятельности возрастает.

- Обучающиеся должны получать указания от преподавателей, чтобы что их стратегии изучения предметной области были применимы как в условиях занятий в классе, так и во внеаудиторной учебной деятельности.

- Многие обучающиеся могут идентифицировать и получать ресурсы, используя их для построения своей траектории обучения английскому языку, применять или преобразовывать полученные знания, оценивать их полезность и т.д.

- Следует просить обучающихся записывать и документировать свои результаты своей практиче- ской учебной деятельности. Здесь приемлемы записи на мобильном устройстве, фотографии, видео. Важно, что все это дает преподавателю «общее понимание» стратегий изучения предметной области, выбираемых разными членами учебной группы. Следует также поощрять как можно более критические отзывы и обмен различными мнениями.

- Обучающиеся должны также определиться, каким образом они будут работать, с кем они будут работать и какие инструменты и СМИ предполагается использовать как в процессе учебной работы в классе, так и в рамках внеаудиторной учебной деятельности.

Таким образом, сочетание правильного выбора педагогических технологий и возможность доступа к информационным ресурсам «в любом месте», для записи и упорядоченного хранения актуальной информации, имеющей отношение к конкретному фрагменту образовательного процесса, полученному обучающимся через доступные мобильные устройства является необходимым условием существенного прогресса в успешной деятельности по освоению учебного контента, что подобно описано в данной статье.

\section{ЛИТЕРАТУРА}

1. Бектурганова М.К., Син Е.Е. Мобильное обучение как новый подход в вузовском образовании // Научный форум: Педагогика и психология: сб. ст. по материалам V междунар. науч.-практ. конф. - М.: МЦНО. - 2017. - № 3(5). - С. 24-30.

2. Жилина А.И. Системно-деятельностный подход учителя к управлению знаниями учащихся на уроке в соответствии с требованиями ФГОС // Человек и образование. - 2017. - №4. - С. 59-64.

3. Касаткина Н.Н. Исследование готовности студентов вузов к мобильному обучению // Ярославский пед. вестн. - 2017. - № 6. - С. $133-138$.

4. Ковалева Н.Б. Медиаобразовательные перспективы рефлексивно-позиционного развития личности и способностей учащихся // Медиаобразование. Media Education. - 2017. - № 1(19). - C. 9-22.

5. Комаров К.Ю. Развитие территориального (регионального) пространства непрерывного профессионального образования: методология, теория, практика: монография / К.Ю. Комаров; под ред. В.А. Федорова. Екатеринбург: Изд-во Рос. гос. проф.-пед. ун-та, 2015. 244 с.

6. Куклев В.А Становление системы мобильного обучения в открытом дистанционном образовании // Школьные технологии. - 2010. - № 4. - С. 45-52.

7. Логинова А.В. Использование технологии мобильного обучения в образовательном процессе // Молодой учёный. - 2015. - №8. - С. $974-976$.

8. Рябкова В.В. Интеграция мобильных технологий в процесс обучения (начальный этап) // Педагогические науки. - №5 (59). - 2017. - С. $21-25$.

9. Слободчиков В.И. Антропология образования - как предчувствие смысла // Наука и школа. - 2015. - № 6. - С. 138-142.

10. Федоров А.В., Новикова А.А. Медиаобразование в ведущих странах Запада. - Таганрог: Изд-во Кучма, 2020. - 270 с.

11. Фундаментальное ядро содержания общего образования / под ред. В.В. Козлова, А.М. Кондакова. - М.: Просвещение, 2019. - 79 с.

12. Чепуренко Г.П. Обеспечение результативности обучения в условиях информатизации образования в вузе // Вестн. ЛГУ им. А.С. Пушкина. - 2018. - №2. - C. 306-318.

13. Юрьева Д.В. Мобильное обучение в управлении знаниями: проблемы эффективности. // Педагогика и просвещение. - 2019. - № 3. DOI: 10.7256/24540676.2019.3.30367 URL: https://nbpublish.com/library_read_article.php?id=30367

14. Kisko, D. Questions That Will Help Revamp Your Mobile Learning Strategies - URL: http://www.k12mobilelearning.com/questions-to-help-revamp-your-mobilelearning-strategies

15. Rushby, N Editorial: An agenda for mobile learning. British Journal of Educational Technology (2012) 43/3: 355-356.

16. Pegrum, M Mobile Learning: Languages, Literacies and Cultures Basingstoke: Palgrave Macmillan. (2014).

( ) Богоносов Константин Александрович (kbogonosov@gmail.com), Воробьев Дмитрий Игоревич (d.vorobyev@mgutm.ru), Пономарева Лиля Фаясовна (eponomarev@mfmgutu.ru), Садекова София Равилевна (s.sadekova@mgutm.ru), моисеев Виктор Александрович.

Журнал «Современная наука: актуальные проблемы теории и практики» 